\title{
Importance of Late Fall ENSO Teleconnection in the Euro-Atlantic Sector
}

\author{
Martin P. King, Ivana Herceg-Bulić, Ileana Bladé, Javier García-Serrano, Noel Keenlyside, \\ Fred Kucharski, Camille Li, Stefan Sobolowski
}

A s a prominent component of the climate system on interannual time scales, El Niño-Southern Oscillation (ENSO) significantly affects the seasonal climate of many local and remote regions. Many studies have investigated the remote impacts and dynamics of ENSO teleconnections, mostly focusing on boreal winter. In comparison, we have a more limited understanding of the fall ENSO teleconnection and therefore may not fully recognize its potential importance. This article aims to highlight the late fall and early winter (November and December) ENSO teleconnection to the North Atlantic-European (NAE) sector. Exploratory analyses are presented, and a number of future research directions are proposed.

To the extent that the ENSO phenomenon is predictable, its teleconnections can provide a source of predictability for climate variability and change in the affected remote regions. A better knowledge of ENSO teleconnection dynamics may also motivate model improvements (Scaife et al. 2014). Our discussion primarily concerns linear ENSO teleconnections

AFFILIATIONS: KING AND SOBOLOWSKI-Uni Research Climate, and Bjerknes Centre for Climate Research, Bergen, Norway; HERCEG-BULIĆ-Department of Geophysics, University of Zagreb, Zagreb, Croatia; BLADÉ-Group of Meteorology, Department of Applied Physics, University of Barcelona, Barcelona, Spain; García-Serrano-Barcelona Supercomputing Center, Barcelona, Spain; KeENLYSIDE AND LI-Geophysical Institute, University of Bergen, and Bjerknes Centre for Climate Research, Bergen, Norway; KUCHARSKI-Abdus Salam International Centre for Theoretical Physics, Trieste, Italy CORRESPONDING AUTHOR: Martin P. King, martin.king@uni.no

DOI:10.1175/BAMS-D-17-0020.I

(C) 2018 American Meteorological Society

For information regarding reuse of this content and general copyright information, consult the AMS Copyright Policy. related to the Niño-3.4 index, so we do not address the asymmetry between cold and warm phases, nor do we distinguish between central Pacific and eastern Pacific ENSO, although these aspects might be important (Pozo-Vázquez et al. 2001; Garfinkel et al. 2013; Frauen et al. 2014; Feng et al. 2017).

The extratropical atmospheric response to ENSO in the Northern Hemisphere (NH) winter is most prominent over the North Pacific-American (NPA) sector and is characterized by a Rossby wave train that arches northeastward [see Trenberth et al. (1998) and Alexander et al. (2002) for reviews]. Although this wave-like structure is often referred to as the Pacific-North American (PNA) pattern, it is actually in quadrature with the PNA and is more reminiscent of the Tropical-Northern Hemisphere (TNH) pattern (Nigam and Baxter 2014). Despite the fact that the SST anomalies in the tropical Pacific are already strong in fall, this ENSO-forced Rossby wave train is not fully established until January (see Fig. 1c; Bladé et al. 2008).

While the impact of ENSO on the NPA region is distinct and strong, its effects in the NAE region are weaker and more challenging to demonstrate. Some studies have reported statistically significant signals in observational data and climate reconstructions, some of which have been qualitatively reproduced in numerical model simulations (Brönnimann 2007 and references therein; Herceg-Bulić 2012; Shaman 2014; Shaman and Tziperman 2011). Generally, the wintertime El Niño impact in the NAE sector manifests as a meridional pressure dipole, with increased pressure to the north and decreased pressure to the south (see Fig. 1c; García-Serrano et al. 2011). However, there is still debate over the robustness and spatiotemporal characteristics of this teleconnection, and an incomplete understanding of the underlying mechanisms.

For the ENSO-to-NAE teleconnection, the classical explanation of a tropospheric Rossby wave 
a) Nov

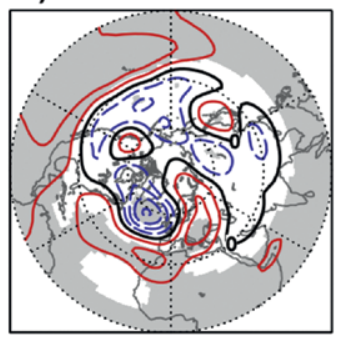

b) Dec
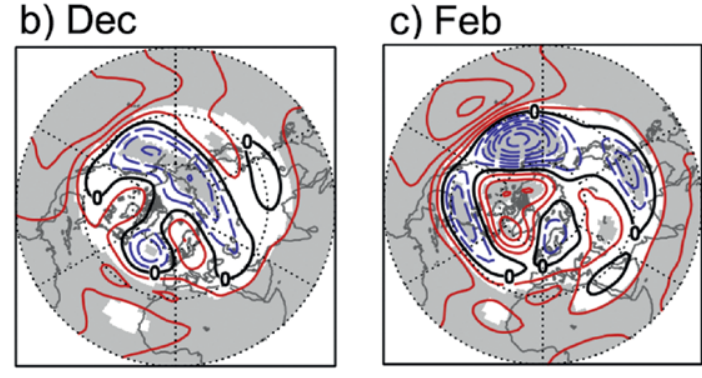

FIG. I. Regressions of Z200 in (a) Nov, (b) Dec, and (c) Feb on the mean Niño-3.4 index in Sep-Nov, Oct-Dec, and Dec-Feb, respectively. Contour interval is $10 \mathrm{~m}$. Shading indicates statistical significance at the $95 \%$ level according to a two-tailed $t$ test. All panels have pfield $<0.1 \%$ for regions poleward of $20^{\circ} \mathrm{N}$. Original data are from NCEP-NCAR Reanalysis and HadISST for 1948-20I5.

emanating from the tropics and propagating to the midlatitudes may not be the complete story. Wang (2005) has offered an alternative perspective involving altered Walker and Atlantic Hadley circulation cells. The stratosphere is also believed to be important: ENSO-induced planetary waves can propagate into the stratosphere and induce sudden warmings, leading to circulation anomalies that descend into the troposphere and affect surface climate, primarily in the NAE sector (Manzini et al. 2006; Bell et al. 2009; Cagnazzo and Manzini 2009; Ineson and Scaife 2009; Butler et al. 2014; Richter et al. 2015; Herceg-Bulić et al. 2017). According to some studies, a realistic representation of the ENSO impact in Europe requires a model with a fully resolved stratosphere that is capable of simulating this chain of events (e.g., Scaife et al. 2014). A "high top" model, however, does not guarantee a correct simulation of the ENSO signal, and some models regarded as "low top" produce realistic results.

A number of factors contribute to the less distinct nature of the NAE teleconnection. Transient eddy feedbacks and air-sea interactions are important (Watanabe and Kimoto 1999; Pan 2005), with North Atlantic SSTs playing a possible role in delaying the response to ENSO or modifying it to project onto the North Atlantic Oscillation (Herceg-Bulić and Kucharski 2012). A more general challenge for simulating ENSO impacts is the chaotic nature of the midlatitude atmosphere, which reduces the signal-tonoise ratio and limits predictability, also giving rise to uncertainty on what the real-world teleconnection actually is (Deser et al. 2017). Finally, ENSO teleconnections may be modulated by multidecadal variability (López-Parages et al. 2014), climate shifts (King et al. 2017), or global warming (Herceg-Bulić et al. 2012).
The ENSO signal in the NAE sector is known to exhibit intraseasonal variation (Fraedrich 1990; Moron and Gouirand 2003; Shaman 2014; King et al. 2017; Scaife et al. 2017). In fact, the entire NH ENSO teleconnection evolves through the cold season, as seen in Fig. 1, which shows regressions of 200-hPa geopotential height (Z200) onto the Niño-3.4 index. Interestingly, in November the signal is most defined and significant in the NAE sector and resembles the East Atlantic (EA) pattern (Fig. 1a). December appears to be a transitional period during which the EA-like pattern weakens and anomalies in the North Pacific sector begin to develop (Fig. 1b). Finally, in January and February, the canonical Rossby wave train response emerges in the NPA region (represented by February here; Fig. 1c); in the NAE sector, instead the signal is now weak and indistinct, and it is largely not statistically significant. A Student's $t$ test for statistical significance is performed gridpoint-wise (local test); field significance $\left(p_{\text {field }}\right.$ ) (Wilks 2016 and references therein) estimates are also indicated (see caption). The $p_{\text {field }}$ value is the probability of obtaining, by a random process, a greater number of points that are locally significant than found in the pattern being tested (accounting for spatial autocorrelation).

The signals of interest are robust to the choice of averaging period and dataset. The monthly variance of Z200 data are, as expected, larger than the seasonal variance; however, the monthly regressions on the Niño-3.4 index can also be stronger than seasonal regressions because the teleconnection may be stronger in a particular month. As a result, the ratio of the regression magnitude to the total standard deviation in the NAE sector is comparable (maximum of 0.4 ) for monthly and seasonal means. The patterns shown in Fig. 1 are also robust across different datasets and periods for the instrumental and reanalysis eras [Second Hadley Centre Sea Level Pressure dataset (HadSLP2r), European Centre for Medium-Range Weather Forecasts (ECMWF) interim reanalysis (ERA-Interim; see Fig. 4), and National Oceanic and Atmospheric Administration/Cooperative Institute for Research in Environmental Studies (NOAA/CIRES) TwentiethCentury Reanalysis]. The reproducibility of the strong November ENSO teleconnection in the NAE sector is 


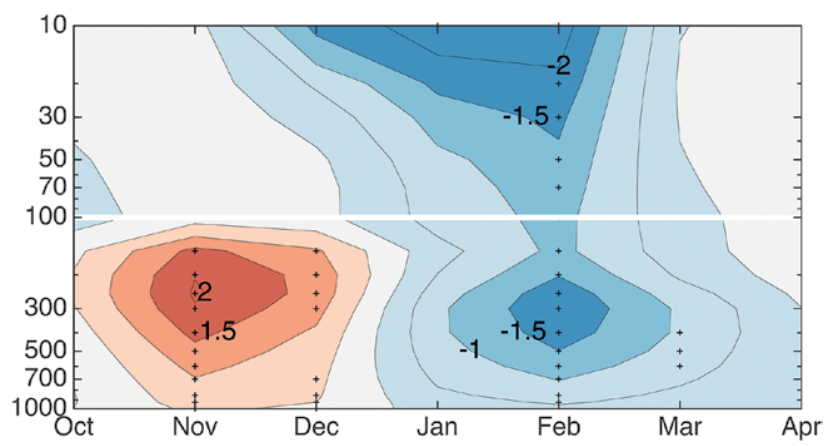

FIG. 2. Regression of zonal wind ( $\left.\mathrm{m} \mathrm{s}^{-1}\right)$ on the Niño-3.4 index on a pressure level-month plane. The zonal wind time series is defined as the area average of the zonal wind in the area $40^{\circ}-50^{\circ} \mathrm{N}, 90^{\circ} \mathrm{W}-0^{\circ}$ for levels below $100 \mathrm{hPa}$, and the zonal mean is in the latitude band $50^{\circ}-60^{\circ} \mathrm{N}$ for levels at and above $100 \mathrm{hPa}$ (see text). The crosses mark values with statistical significance at the $95 \%$ level according to a two-tailed $t$ test. Original data are from NCEP-NCAR Reanalysis and HadISST. discussed in more detail in King et al. (2017), who investigate the spatiotemporal variability of this teleconnection and also show that two atmospheric models forced with observed SSTs qualitatively reproduce this fall ENSO signal.

Figure 2 shows the October-April evolution of the ENSO-related zonal wind field. An altitude-dependent zonal wind anomaly time series was constructed after examining the zonal wind regressions on the Niño-3.4 index level by level. For the troposphere (below $100 \mathrm{hPa}$ ), we average over the central Atlantic $\left(40^{\circ}-50^{\circ} \mathrm{N}, 90^{\circ}-0^{\circ} \mathrm{W}\right)$; for the stratosphere, we take the zonal average from $50^{\circ}$ to $60^{\circ} \mathrm{N}$, a choice that reflects the fact that ENSO zonal wind anomalies are more zonally symmetric and northward shifted in the stratosphere. In November, anomalous Atlantic westerlies extend through the depth of the troposphere [consistent with Scaife et al. (2017) and our Fig. 1a] but are not associated with a preceding or concurrent signal in the stratosphere. This signal decays in a) Nov surface temperature

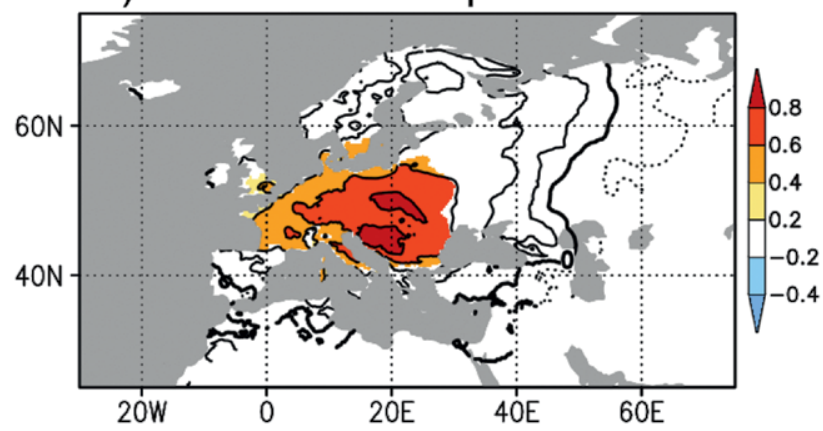

c) Feb surface temperature

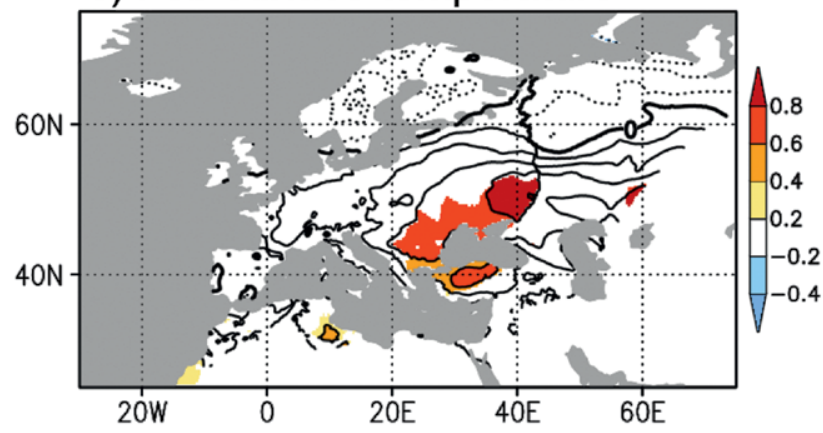

b) Dec surface temperature

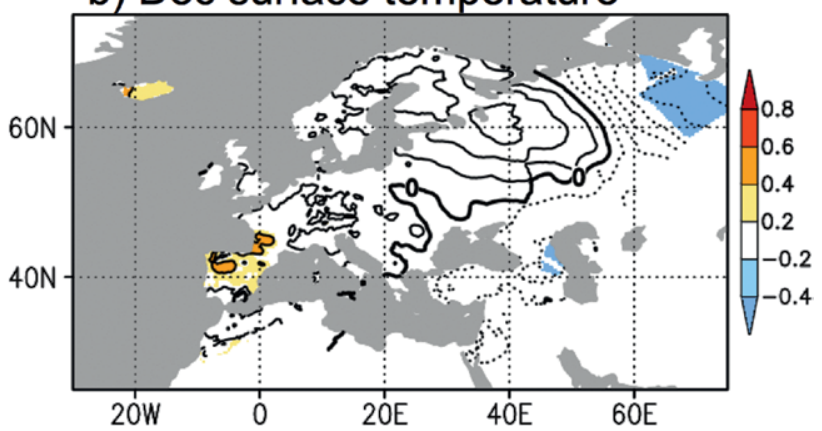

d) Nov precipitation

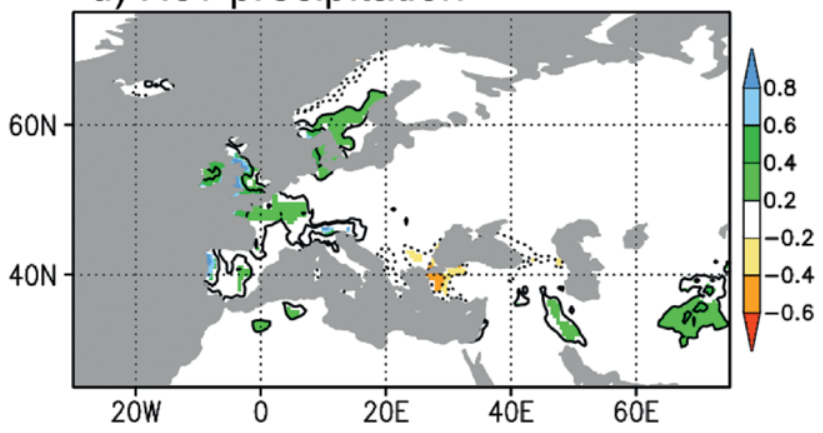

FIG. 3. (a)-(c) As in Fig. I, but for E-Obs surface air temperature during 1950-20I5. Contour interval is $0.2 \mathrm{~K}$. Shading indicates both positive values and statistical significance at the $95 \%$ level from a local two-tailed $t$ test. In (a), p pield < 5\%, while in (b) and (c), pfield > 20\%. (d) The regression of CRU precipitation in Nov on the mean Sep-Nov Niño-3.4 index for 1950-2015. Contour lines are at -0.4, -0.2, 0.2, and 0.4. Shading indicates both an anomaly and statistical significance at the $90 \%$ level from a local two-tailed $t$ test. In (d) pfield $<5 \%$. 
December and is replaced by tropospheric easterly anomalies that peak in February and, in contrast with the November signal, are accompanied by zonal-mean easterly anomalies in the stratosphere, which appear to develop as early as December. While the latter result is consistent with the notion of a downward stratospheric pathway in midwinter (Bell et al. 2009), the mechanism for the tropospheric-only ENSO teleconnection in late fall is not clearly understood. While a diagnosis of this signal is beyond the scope of this paper, we speculate that the marked differences between the late fall and midwinter ENSO teleconnection are due to a combination of differences in the background atmospheric flow and associated Rossby waveguide, the preferred mode of natural variability, and stratospheric preconditioning.

Over Europe, the temperature signal associated with ENSO is substantial in November (Fig. 3a), with widespread positive anomalies across central Europe during El Niño events, which contrast with the weak and nonsignificant anomalies seen in later months (at least for the data examined here). For one standard deviation of the Niño-3.4 index, the associated temperature anomalies in November are up to $0.8 \mathrm{~K}$ across much of Europe (Fig. 3a); moreover, both the daily maximum and minimum temperatures increase by $0.8-1.0 \mathrm{~K}$ (not shown). As for the ENSOrelated precipitation signal, no significant anomalies are found from December to March. For November, some precipitation datasets [the Climate Research Unit Time Series (CRU TS) and Global Precipitation Climatology Centre, version 7 (GPCC V7) datasets, but not the European daily high-resolution gridded dataset (E-Obs $0.25^{\circ}$ )] show a marginally significant (at the 90\% level) signal in western Europe, such that a positive (negative) Niño-3.4 is associated with positive (negative) anomalies (Fig. 3d). We caution, however, that establishing a relationship between ENSO and precipitation in areas the $95 \%$ level. outside the tropics can be challenging and problematic (van Oldenborgh and Burgers 2005).

Figure 4 shows the Z200 patterns related to Niño3.4 in ERA-Interim (top) compared to the ECMWF System 4 (Sys4) seasonal hindcast (bottom) for the 1981-2012 period (15 ensemble members initialized on 1 November). The spatial correlation (poleward of $20^{\circ} \mathrm{N}$ ) between the $\mathrm{Z} 200$ teleconnections in the two datasets increases from 0.41 in November to 0.62 in December and 0.72 in February, suggesting that the ENSO teleconnection might be better simulated spatially as winter progresses. In November (Figs. 4a,d), ECMWF Sys4 overestimates the magnitude and spatial extent of the signal in the North Pacific. It also underestimates the signal in the North Atlantic, but the patterns are remarkably similar, including two small anticyclonic anomalies in the subtropical Atlantic. In February (Figs. 4c,f), the centers of action of the ENSO anomalies are well simulated overall. More detailed analysis is needed to assess the general performance of models in simulating the ENSO teleconnection in the cold seasons and its transition from late fall to winter and to determine whether improvement is needed (see also question 2 below).
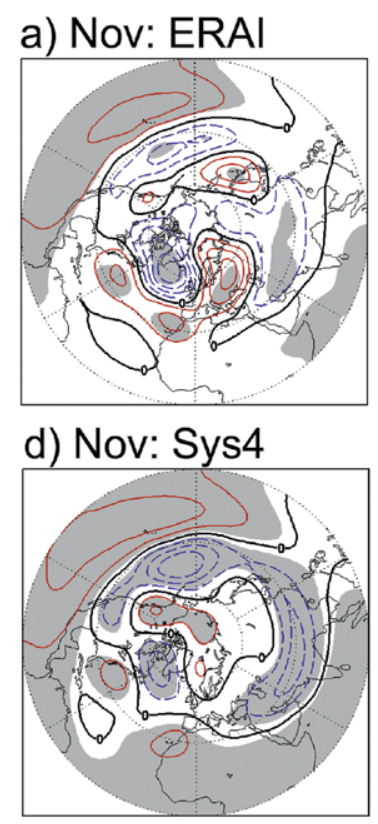

b) Dec: ERAI

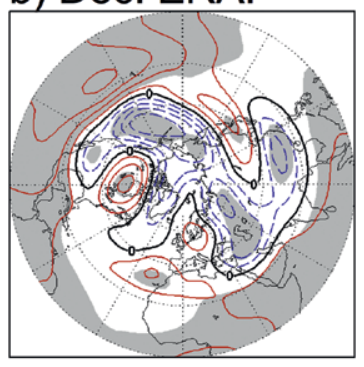

e) Dec: Sys4

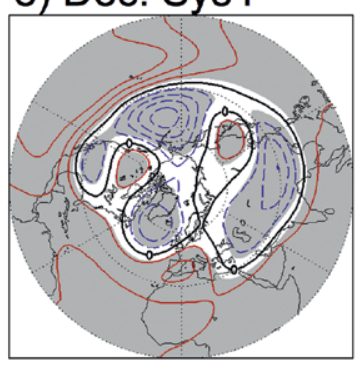

c) Feb: ERAI

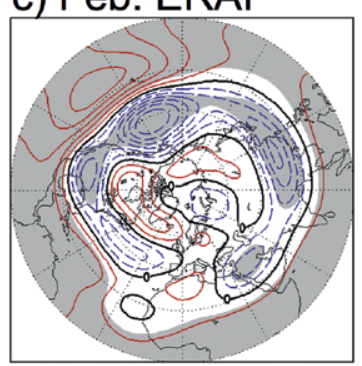

f) Feb: Sys 4

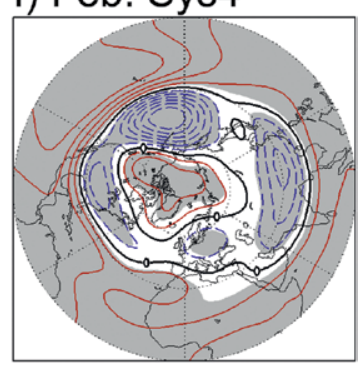

Fig. 4. Regressions of Z200 in (a),(d) Nov, (b),(e) Dec, and (c),(f) Feb on the mean Niño-3.4 index in the respective months. Original data are from (a)(c) ERA-Interim and (d)-(f) ECMWF Sys4 hindcast for 198I-20I2. Spatial correlations of $\mathrm{NH}$ area $\left(20^{\circ}-90^{\circ} \mathrm{N}\right)$ between the top and bottom panels in each column are $0.41,0.62$, and 0.72 , respectively. Contour interval is $10 \mathrm{~m}$. Shading indicates statistical significance according to a two-tailed $t$ test at 
The spatial correlations described above indicate how well the model simulates the ENSO teleconnection spatially over the hindcast period but not the model's prediction skill. To assess prediction skill, we can define a time series for the November EA-like pattern by taking the area-averaged 500 -hPa geopotential height (Z500) in the region $20^{\circ}-40^{\circ} \mathrm{N}, 90^{\circ} \mathrm{W}-0^{\circ}$ minus the average in the region $50^{\circ}-65^{\circ} \mathrm{N}, 60^{\circ} \mathrm{W}-0^{\circ}$ (the two centers of the EA-like pattern) and then calculating its temporal correlation with the corresponding time series from ERA-Interim. The EA time series for the ensemble-mean hindcast and ERA-Interim are correlated at 0.75 (individual members' correlations: $0.20,0.26,0.33,0.38,0.4,0.4,0.42,0.46,0.47,0.49,0.5$, $0.54,0.54,0.56,0.66)$. Commonly, the ensemble mean achieves a higher correlation with observation than any individual member because ensemble averaging has removed the unpredictable noise. Recently, Scaife et al. (2017) presented case studies for two strong El Niño episodes (a hindcast for 1982/83 and a real-time forecast for 2015/16) using the UK Met Office's GloSea5 seasonal prediction system. They showed that the model accurately predicts the strong anomalous westerlies in the central North Atlantic in November and December that led to intense rainfall across western Europe, as well as the transition to weaker westerly flow in January and February (see their Figs. 3 and 4). Taken together, these results are encouraging because they suggest that the model can simulate the intraseasonal changes in the background flow, Atlantic SSTs, and other dynamical changes that occur in nature that lead to differences in the remote ENSO teleconnection across the cold season.

The basic analyses presented here indicate that the ENSO teleconnection to the NAE sector in November and December is both stronger and different than in January and February, with a distinct EA-like dipole pattern that is absent in midwinter. The ENSO impact on surface climate in this region also appears to be stronger in November. That the ENSO signal in the Atlantic varies from late fall to winter is not entirely a new result (e.g., Moron and Gouirand 2003); the added value here is we have shown that the atmospheric and surface climate differences are robust, that the former extends to the stratosphere, and that the signal is reproduced in the ECMWF Sys4. A corollary of our results is that conventional winter-mean (December-February or December-March) analyses may obscure important intraseasonal features of the ENSO teleconnection, as has been previously discussed (e.g., Bladé et al.
2008). Recognizing this, some studies have analyzed January and February means (Toniazzo and Scaife 2006; García-Serrano et al. 2011), which we hope will become customary practice.

The analyses and discussion presented in this article raise a number of outstanding questions:

1) What is the physical explanation for the differences between the November and December and the January and February ENSO teleconnection in the NAE sector? Do the background states of the troposphere and stratosphere, synoptic processes, internal variability, or North Atlantic air-sea interactions play a role? Forcings from other ocean basins (the tropical Atlantic and Indian Oceans) "teleconnected" to ENSO may also modulate the transition of the response from fall to winter. A preliminary analysis of the anomalous Rossby wave source and wave activity flux suggests a different extratropical path for the ENSO teleconnection in late fall compared with midwinter, with an indication that in the first case propagation is more confined to the Atlantic basin rather than taking place via the NPA region.

2) To what extent can the ENSO-related EA-like signal account for fall climate anomalies in Europe? Why is the ENSO-related precipitation anomaly difficult to identify and weak in both fall and winter?

3) How well do models simulate late fall ENSO-related atmospheric patterns and surface climate anomalies in space and time? What are the critical model components?

4) What is the implication for subseasonal-to-seasonal climate forecasts? Can information about ENSO be exploited to improve climate forecasts for the NAE sector? What is the prediction skill for late fall NAE climate variability related to ENSO? Is there any lagged influence that could further improve predictability for the months following November and December?

5) Could global warming, Arctic forcing, or multidecadal climate variability modulate these teleconnections?

Studies addressing these questions already exist (see selected papers in "For Further Reading"), but these questions involve processes that are still not well understood. In our view, progress in research related to these issues has potential benefits for seasonal climate forecasts, attribution of climate impacts or events, and climate model improvement. 
ACKNOWLEDGMENTS. We gratefully acknowledge the National Centers for Environmental Prediction (NCEP)-National Center for Atmospheric Research (NCAR) Reanalysis 1 (R-1), ERA-Interim, E-Obs, CRU TS, Hadley Centre Sea Ice and Sea Surface Temperature dataset (HadISST), and ECMWF Sys4 hindcasts datasets. MPK, CL, and SS are partially supported by the Research Council of Norway's Klimaforsk program (Project 255027), IHB by the Croatian Science Foundation (Project 2831), and IB and JG-S by the Spanish MINECO-funded DANAE project (CGL2015-68342-R). Comments from Dr. M. A. Alexander (editor) and three reviewers have helped to improve this article.

\section{FOR FURTHER READING}

Alexander, M. A., I. Bladé, M. Newman, J. R. Lanzante, N.-C. Lau, and J. D. Scott, 2002: The atmospheric bridge: The influence of ENSO teleconnections on air-sea interaction over the global oceans. J. Climate, 15, 2205-2230, https://doi.org/10.1175/1520 -0442(2002)015<2205:TABTIO >2.0.CO;2.

Bell, C. J., L. J. Gray, A. J. Charlton Perez, and M. M. Joshi, 2009: Stratospheric communication of El Niño teleconnections to European winter. J. Climate, 22, 4083-4096, https://doi.org/10.1175/2009JCLI2717.1.

Bladé, I., M. Newman, M. A. Alexander, and J. D. Scott, 2008: Late fall extratropical response to ENSO: Sensitivity to coupling and convection in the tropical West Pacific. J. Climate, 21, 6101-6118, https://doi .org/10.1175/2008JCLI1612.1.

Brönnimann, S., 2007: Impact of El Niño-Southern Oscillation. Rev. Geophys., 45, RG3003, https://doi .org/10.1029/2006RG000199.

Butler, A. H., L. M. Polvani, and C. Deser, 2014: Separating the stratospheric and tropospheric pathways of $\mathrm{El}$ Niño-Southern Oscillation teleconnections. Environ. Res. Lett., 9, 024014, https://doi.org/10.1088/1748 $-9326 / 9 / 2 / 024014$

Cagnazzo, C., and E. Manzini, 2009: Impact of the stratosphere on the winter tropospheric teleconnections between ENSO and the North Atlantic and European Region. J. Climate, 22, 1223-1238, https:// doi.org/10.1175/2008JCLI2549.1.

Deser, C., I. Simpson, K. McKinno, and A. Phillips, 2017: The Northern Hemisphere extra-tropical atmospheric circulation response to ENSO: How well do we know it and how do we evaluate models accordingly? J. Climate, 30, 5059-5082, https://doi .org/10.1175/JCLI-D-16-0844.1.
Feng, J., W. Chen, and Y. Li, 2017: Asymmetry of the winter extra-tropical teleconnections in the Northern Hemisphere associated with two types of ENSO. Climate Dyn., 48, 2135-2151, https://doi.org/10.1007 /s00382-016-3196-2.

Fraedrich, K., 1990: European grosswetter during the warm and cold extremes of the El Nino/Southern Oscillation. Int. J. Climatol., 10, 21-31, https://doi .org/10.1002/joc.3370100104.

Frauen, C., D. Dommenget, N. Tyrrell, M. Rezny, and S. Wales, 2014: Analysis of the nonlinearity of El Niño-Southern oscillation teleconnections. J. Climate, 27, 6225-6244, https://doi.org/10.1175/JCLI -D-13-00757.1.

García-Serrano, J., B. Rodríguez-Fonseca, I. Bladé, P. Zurita-Gotor, and A. de la Cámara, 2011: Rotational atmospheric circulation during North Atlantic-European winter: the influence of ENSO. Climate Dyn., 37, 1727-1743, https://doi.org/10.1007/s00382-010-0968-y. Garfinkel, C. I., M. M. Hurwitz, D. W. Waugh, and A. H. Butler, 2013: Are the teleconnections of CentralPacific and Eastern-Pacific El Niño distinct in boreal wintertime? Climate Dyn., 41, 1835-1852, https://doi .org/10.1007/s00382-012-1570-2.

Herceg-Bulić, I., 2012: The sensitivity of climate response to the wintertime Niño3.4 sea surface temperature anomalies of 1855-2002. Int. J. Climatol., 32, 22-32, https://doi.org/10.1002/joc.2255.

—-, and F. Kucharski, 2012: Delayed ENSO impact on spring precipitation over North/Atlantic European region. Climate Dyn., 38, 2593-2612, https://doi .org/10.1007/s00382-011-1151-9.

—, Č. Branković, and F. Kucharski, 2012: Winter ENSO teleconnections in a warmer climate. Climate Dyn., 38, 1593-1613, https://doi.org/10.1007/s00382 -010-0987-8.

-, B. Mezzina, F. Kucharski, P. Ruggieri, and M. P. King, 2017: Wintertime ENSO influence on late spring European climate: the stratospheric response and the role of North Atlantic SST. Int. J. Climatol., 37, 87-108, https://doi.org/10.1002/joc.4980.

Ineson, S., and A. Scaife, 2009: The role of the stratosphere in the European climate response to El Niño. Nat. Geosci. 2, 32-36, https://doi.org/10.1038 /ngeo381.

King, M. P., I. Herceg-Bulić, F. Kucharski, and N. Keenlyside, 2017: Interannual tropical Pacific sea surface temperature anomalies teleconnection to Northern Hemisphere atmosphere in November. Climate Dyn., 50, 1881-1899, https://doi.org/10.1007 /s00382-017-3727-5. 
López-Parages, J., B. Rodríguez-Fonseca, and L. Terray, 2015: A mechanism for the multidecadal modulation of ENSO teleconnection with Europe. Climate Dyn., 45, 867-880, https://doi.org/10.1007/s00382-014-2319-x.

Manzini, E., M. A. Giorgetta, L. Kornblueh, and E. Roeckner, 2006: The influence of sea surface temperatures on the northern winter stratosphere: Ensemble simulations with the MAECHAM5 model. J. Climate, 19, 3863-3881, https://doi.org/10.1175/JCLI3826.1.

Moron, V., and I. Gouirand, 2003: Seasonal modulation of the El Niño-Southern Oscillation relationship with sea level pressure anomalies over the North Atlantic in October-March 1873-1996. Int. J. Climatol., 23, 143-155, https://doi.org/10.1002/joc.868.

Nigam, S., and S. Baxter, 2014: Teleconnections. Encyclopedia of Atmospheric Sciences, 2nd ed. G. North, F. Zhang, and J. Pyle, Eds., Academic Press/Elsevier Science, 90-109.

Pan, L.-L., 2005: Observed positive feedback between the NAO and the North Atlantic SSTA tripole. Geophys. Res. Lett., 32, L06707. https://doi .org/10.1029/2005GL022427.

Pozo-Vázquez, D., M. J. Esteban-Parra, F. S. Rodrigo, and Y. Castro-Díez, 2001: The Association between ENSO and winter atmospheric circulation and temperature in the North Atlantic region. J. Climate, 14, 3408-3420, https://doi.org/10.1175/1520 -0442(2001)014<3408:TABEAW>2.0.CO;2.

Richter, J. H., C. Deser, and L. Sun, 2015: Effects of stratospheric variability on El Niño Teleconnections. Environ. Res. Lett., 10, 124021, https://doi .org/10.1088/1748-9326/10/12/124021.

Scaife, A., and Coauthors, 2014: Skillful long-range of European and North American winters. Geophys. Res. Lett., 41, 2514-2519, https://doi.org/10.1002/2014GL059637. - , and - 2017: Predictability of European winter 2015/2016. Atmos. Sci. Lett., 18, 38-44, https://doi .org/10.1002/asl.721.
Shaman, J., 2014: The seasonal effects of ENSO on atmospheric conditions associated with European precipitation: Model simulations of seasonal teleconnections. J. Climate, 27, 1010-1028, https://doi. org/10.1175/JCLI-D-12-00734.1.

—-, and E. Tziperman, 2011: An atmospheric teleconnection linking ENSO and southwestern European precipitation. J. Climate, 24, 124-139, https://doi. org/10.1175/2010JCLI3590.1.

Toniazzo, T., and A. A. Scaife, 2006: The influence of ENSO on winter North Atlantic climate. Geophys. Res. Lett., 33, L24704, https://doi. org/10.1029/2006GL027881.

Trenberth, K. E., G. W. Branstator, D. Karoly, A. Kumar, N.-C. Lau, and C. Ropelewski, 1998: Progress during TOGA in understanding and modeling global teleconnections associated with tropical sea surface temperatures. J. Geophys. Res., 103, 14291-14324, https://doi.org/10.1029/97JC01444.

van Oldenborgh, G. J., and G. Burgers, 2005: Searching for decadal variations in ENSO precipitation teleconnections. Geophys. Res. Lett., 32, L15701, https://doi. org/10.1029/2005GL023110.

Wang, C., 2005: ENSO, Atlantic climate variability and the Walker and Hadley circulations. The Hadley Circulation: Present, Past and Future. H. F. Diaz and R. S. Bradley, Eds., Kluwer Academic Publishers, 173-202.

Watanabe, M., and M. Kimoto, 1999: Tropical-extratropical connection in the Atlantic atmosphereocean variability. Geophys. Res. Lett., 26, 2247-2250, https://doi.org/10.1029/1999GL900350.

Wilks, D., 2016: "The stippling shows statistically significant grid points": How research results are routinely overstated, overinterpreted, and what to do about it. Bull. Amer. Soc. Meteor., 97, 2263-2273, https://doi.org/10.1175/BAMS-D-15-00267.1. 
New Benefit for AMS Members!

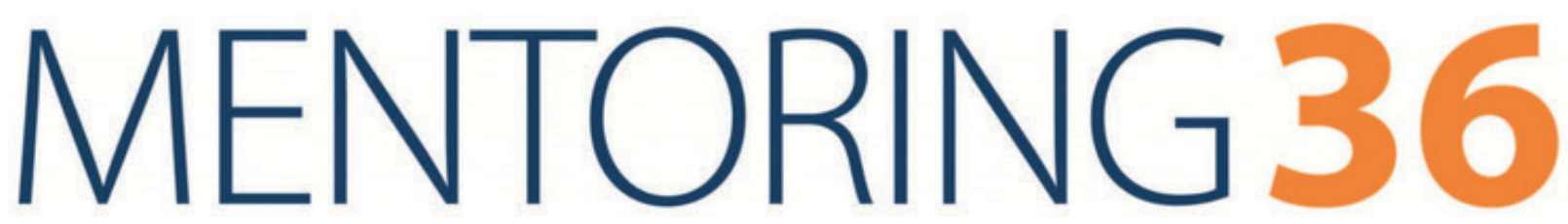

\section{Reach Your Full Potential}

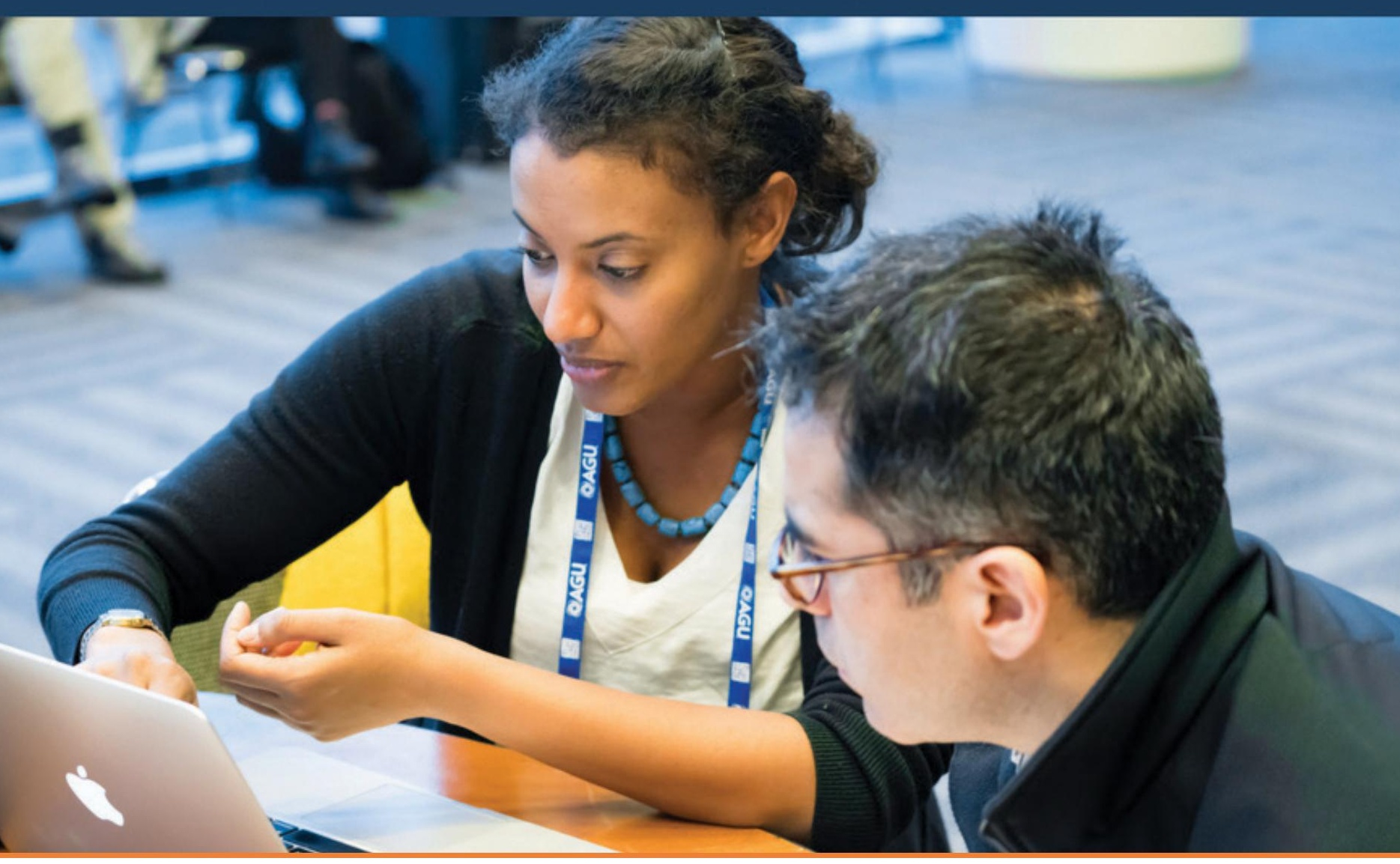

Developed in partnership with Earth and space science organizations, Mentoring365 provides mentors and mentees with structured relationship-building tools to develop and attain focused career goals.

(9) AMS www.mentoring365.org 